\title{
Comparative Myo-architectural Orientation of the Ex- trinsic Lingual Muscles of the Egyptian Cattle (Bos taurus), Buffalo (Bubalus bubalis) and Camel (Camelus dromedarius)
}

\section{A. Nazih}

Department of anatomy, faculty of veterinary medicine, New Valley University, El-Kharga, New Valley, Egypt

With 9 figures, 6 tables Received January and accepted for publication March 2019

\begin{abstract}
Comparative myo-architectural anatomical studies were adopted on both sexes of twelve apparently healthy adults of cattle, buffalo and camel. The study was aimed to describe the architectural orientation of the extrinsic lingual muscles for each species. As well as statistical data between the tongue and extrinsic lingual muscles. The work declared the properties of potent tongue which allowed the cattle and buffalo to perform their behavioral prehension of food. The study described the extrinsic lingual muscles and spotted a light on the role of the geniohyoid muscle on the tongue. The work concluded that the tongue of cattle was stronger than that of buffalo while both were able to depend on their tongue for food prehension. On the other hand, the tongue of camel was found to be adapted for intraoral function.
\end{abstract}

Keywords: Comparative, orientation, lingual muscles, cattle, buffalo, camel.

\section{Introduction}

Tongue was an important musculomembra-nous organ in the oral cavity proper and among the domestic animals, cattle depend up on it mainly for food prehension Iwasaki (2002) in vertebrate and Igado (2011) in dog. However, horse, camel, sheep and goat utilized their flexible lips for cutting the grasses. Dog and cat used their incisors and canine teeth with jerking movement of the head and neck to pick up their food.

Studying importance of the tongue shifted the interest of many authors, Wedeen et al. (2001) in bovine, Chibuzo (2006) in goat, Saidu et al. (2015) in camel. Other anatomists spotted their studies on the lingual papillae scanning, Parvez and Rahman (2005) in cow and Eerdunchaolu et al. (2008) in camel. A morphometric study was permitted by Igado (2011) in dog, El- bably and Tolba (2015) in cat as well as Shoeib et al. (2014) in carnivores and camel. 
The myoarchitectural configuration of the extrinsic lingual muscles among the available literatures were scanty and the present study aimed to spot a light on it to explore the anatomical comparative variations among the Egyptian large ruminants as well as to explain the anatomical abilities of the bovine tongue role on food prehension. Why the bovines and buffaloes depend up on their tongues for food uptake?

\section{Material and Methods}

The work in this study was based on obtaining 12 freshly cut heads of cattle, buffalo and camel of both apparently healthy adult sexes, collected from the slaughtering house in Cairo. The collected heads were arranged as four heads for each species and were washed perfectly under running water and preserved in $10 \%$ formalin solution for four days.

The dissection of the formalized heads started by obtaining the mandible attached with the tongue and hyoid apparatus. The study aimed to describe the extrinsic lingual myoarchitectural features with morphometrical measurements. The latter, determined the ratio between each extrinsic muscle and the tongue to stand up on its powerful configuration. The data were determined by Vernier caliper. The width and thickness of each lingual extrinsic muscle, as well as the geniohyoideous muscle were reported. The diagrams of (Fig 1 and 2) explain the standards of measurements.

\section{Results}

The extrinsic lingual muscles of cattle, buffalo and camel are styloglossus group, hyoglossus and genioglossus muscles. The former includes major and minor stylogossus muscles. All extrinsic lingual muscles have two portions; extra and intra-lingual as well as rostral (apico-corpus) and caudal (torus) terminations, with the exception of minor styloglossus and hyoglossus muscles which are included in the torus linguae.

\section{1) Styloglossus group (Figs 4\&5)}

There are two styloglossus muscles existing among the tongue of cattle; major and minor. The former, is considered to be the longest extrinsic muscle described and is originated by a very short tendon from the ventrolateral point of the lingual end of stylohyoid process while in camel, it arises with longer tendon.

The major muscle passes ventrally and rostrally to cover the origin of the minor one, it descends on the ventrolateral aspect of the lingual torus and proceeds rostrally where it terminates ventrally to the lingual apex.

The extra glossal part of the muscle is the thinner and in cattle and buffalo, it is originated by narrow fibers and gradually widen rostrally. It extends from the stylohyoid process crossing the lateral aspect of hyoglossus muscle and ends rostrally at the mid-level of the lingual torus. In camel, the muscle is flat along its extension, arising 
from the rostral and angular curvature of the stylohyoid process by a long fan shaped tendon. The muscle extends straightly and rostrally with the longitudinal axis of the tongue, traversing the lateral aspect of the minor styloglossus and hyoglossus muscles.

The intra- glossalpart of the major styloglossus muscle is that part which furnishes muscular bundles and embedded in the intrinsic lingual muscular fibers and considered a stout part of the muscle. It extends rostrally as a direct continuation of the proceeding extra glossal part on the ventral aspect of corpus linguae. At the level of sulcus linguae, the muscle is massively thicker with fan shaped terminated fibers. In cattle and buffalo, (Fig 8A \&B) it receives enforcement muscular fibers derived from the intrinsic longitudinal lingual fibers. The latter forms thick band descending from the dorsal and caudolateral angle of the torus linguae. The fibers pass in rostro ventral direction on the medial aspect of hyoglossus muscle. At the rostral border of the latter, it meets the fibers of styloglossus muscle. In cattle, the muscle band measures about $7-7.3 \mathrm{~cm}$ in length, $0.6-0.7 \mathrm{~cm}$ in width and $1.6-$ $1.8 \mathrm{~cm}$ in height while in buffalo it is about $10.2-10.4 \mathrm{~cm}$ long, $0.3-0.4 \mathrm{~cm}$ wide and $2.8-3 \mathrm{~cm}$ high. This muscular band is absent in camel and replaced by thin fibers arising from the stylohyoid process and crossing the deep face of hyoglossus muscle to join the styloglossus one.
At the level of frenulum linguae, the styloglossus muscle passes with the opposing one on the floor of the lingual apex (Fig 5). The rostral end of the muscular fibers of genioglossus muscle, separate between the opposing styloglossus. In cattle and buffalo, the styloglossus muscle of both sides meet together rostrally to the genioglossus muscle by a very short distance ranged between $1.4-1.5 \mathrm{~cm}$ in cattle and $1.9-2 \mathrm{~cm}$ in buffalo, while in camel they meet after alonger distance of about $2.3-2.5 \mathrm{~cm}$.

The minor styloglossus muscle is a band originated from the stylohyoid process on the medial aspect of the proceeding muscle. It covers the lateral side of the lingual end of the stylohyoid process, the muscle fibers ascend rostrally to the caudolateral border of the torus linguae. At the rostral aspect of the palatoglossal fold, the fibers blend superficially with the intrinsic lingual muscle fibers. The muscle in cattle is quadrilateral in shape (Fig $4 A \& 6 A$ ) and measures about 2.7$2.9 \mathrm{~cm}$ long at horizontal axis and 3.6 $4 \mathrm{~cm}$ long at its longitudinal one, while in buffalo, (Fig 4B\&6B) is fusiform and reaches about $1.8-2 \mathrm{~cm}$ long in horizontal axis and $4-4.2 \mathrm{~cm}$ long in its longitudinal one. In camel, (Fig 4C\&6C) it is originated from the lateral surface of stylohyoid process medially to that of the major one. Its fibers are long and form one unit with the muscular fibers of the hyoglossus muscle. 
2)Hyoglossus muscle (Figs 4,7 \&8) It is a flat nearly quadrilateral muscle, its fibers originated from the ventrolateral border of thyrohyoid and basihyoid. In cattle and buffalo, it is attached to the lingual process of the hyoid bone. The muscle fibers fan out in rostrodorsal direction and incremented with the intrinsic lingual muscular fibers of torus linguae. It has two surfaces and borders; the former comprises the lateral and medial one; the lateral surface is related to the medial aspect of the extra-glossal part of styloglossus muscle. While the medial one is facing the genioglossus muscle and the deep muscular enforcement of the styloglossus muscle. The rostral and caudal borders of the muscle is clearly present, the former is thicker and forms an acute angle with the geniohyoideous muscle. The thicker size is noticed in cattle and buffalo where it is referred to existence of a stout muscular bundle arising from the lingual process of the hyoid bone. It joins and supports the rostral border of hyogolssus muscle. Incamel, this bundle is absent due to absence of the lingual process and the hyoglossus muscle is thinner than that in cattle and buffalo. The caudal border of the hyoglossusmuscle appears nearly vertical with a mild inclinationrostrally. The extraglossal part of the muscle represents the muscular fascicles which originate and reache the level of the dorsal border of the styloglossus muscle. At the latter mentioned border, the muscle fibers are embedded within the intrinsic lingual muscular fibers of torus linguae. In camel, (Figs 4C \&6C) the extra-glossal fibers share the neighboring ones of the minor styloglossus forming common broad muscular band.

3)Genioglossus muscle (Figs 4,5,7 \&8)

The largest extrinsic muscle commonly arises with the geniohyoid muscle, in a fan shaped manner from the depressed fossa which is located caudally to the mandibualr symphysis. Both genioglossus muscles are separated by an areolar space and they support the tongue to the median plane of the mouthfloor. The extraglossal part of the muscle, comprise the fibers which ascend in a fan shaped manner with a caudo-dorsal direction to terminate in the body and root of the tongue. The rostral group of fibersare attached to the intrinsic lingual muscular fibers of lingual body while the caudal ones end at the root of the tongue. The former fibers are thinner and ascend in a nearly vertical manner while they thickening gradually and inclining caudally forming the caudal group. The rostral muscle fibers in cattle, (Fig 5A) erupt by a distance about $6.8-7 \mathrm{~cm}$ from the rostral level of the lower incisive gum. In buffalo, (Fig 5B) it existed by about 10$10.3 \mathrm{~cm}$ while in camel, (Fig $5 \mathrm{C}$ ) it furnishes about $13-13.3 \mathrm{~cm}$. In cattle and buffalo, (Fig 8A \&B) the caudal group of the muscle fibers are inserted in the intrinsic lingual muscle fibers of torus 
linguae, lingual end of stylohyoid process and basihyoid. While in camel, (Fig. 8C) there are no attached fibers to the hyoid bone. The intraglossal part of the muscle appears at the level of the dorsal border of the styloglossus muscle.

The average mandibular length from the level of incisive gum up to the mandibular angle in cattle reaches about 35.4-35.6 cm and 44.7-44.9 cm in buffalo, while in camel it is about 37-37.3 $\mathrm{cm}$. The mandibular symphysis depth reaches about $6.8-6.9 \mathrm{~cm}$ in cattle and $10-10.3 \mathrm{~cm}$ in buffalo (Fig 5A \& 5B) while in camel (Fig $5 \mathrm{C}$ ) it extends for about $13-13.2 \mathrm{~cm}$. This means that, the considerable point of eruption of the genioglossus muscle is so close to the mandibular rostral end in cattle and buffalo (Fig 6). While in camel (Fig 6) it is located near to the mid-point of the mandible.

Geniohyoid muscle (Figs 4, 5, 7 \&8) It is a fuciform muscle that fills the median plane of the ventral aspect of the intermandibular space, running along the ventral border of the genioglossus muscle. Both geniohyoid muscles arise commonly with the tendon of the genioglossus one, the muscle thickness increases gradually at the level of the caudal half of the body of the tongue. It passes caudally to attach to the lingual process of the hyoid bone in cattle and buffalo while in camel, the muscle is triangular in shape as it is thickened at the caudal attachment, so the lingual process is missing and the muscle fibers are inserted in the thyrohyoid process.

\section{Extrinsic lingual muscles and the powerful tongue}

The myo-architectural orientation of the extrinsic lingual muscles determines the strength of the tongue. The potency of the latter in the examined samples for each species is based on the supporting enforcement muscle fibers, the average muscular sizes rationally to that of the tongue (Tables $1,2,3,4,5 \& 6$ ) as well as the role of the geniohyoid muscle in tongue movement. The former, represents the muscular bands which enforce the muscle fibers of the intra-glossal part of the styloglossus muscle as well as the muscular fibers which support the rostral fibers of the hyoglossus muscle as described in cattle and buffalo. In camel, the supportive fibers of minor styloglossus muscle unite to that of the hyoglossus one.

The tables attached, declare the differences between the average sizes of the tongue and correlated extrinsic muscles for each species. They show that each of the extrinsic muscles is different; the styloglossus muscle of cattle is relatively larger than that of buffalo and camel. The hyoglossus of camel is rationally larger than that of cattle. The genioglossus muscle is larger in cattle than camel and smaller in buffalo.

The genioglossus muscle is not an extrinsic lingual muscle. It assists the 
tongue indirectlyand is attached to the lingual process of the hyoid bone. The latter is embedded in the root of the tongue and the action of the muscle allows the hyoid bone to protrude the tongue in cattle and buffalo. In camel, the hyoid bone missed the lingual process and accordingly, the effect of the geniohyoid is to attract the thyrohyoid processes with the larynx to the rostral aspect. It should be noted that the average data of the muscle is listed in the tables among the extrinsic lingual muscles.

The examined samples of the tongue of cattle, buffalo and camel, reveals that the cattle and buffalo's tongue is the strongest than that of camel. An adaptation that assists the cattle and buffalo to perform their behavioral prehension. On the other hand, the anatomical architectural orientation of the camel's extrinsic lingual muscles, restricts the tongue function intraorally.

\section{Discussion}

The present study compared the extrinsic lingual muscles of the large Egyptian ruminants; cattle, buffalo and camel, to stand up on the tongue powerfulness. It revealed that the extrinsic muscles could be classified according to their action into direct and indirect; the former was considered to be the styloglossus group (minor and major), hyoglossus and genioglssus. The indirect one was the geniohyoid muscle. In this aspect, Sisson and Grossman (1975) in horse, Köing and Liebich
(2006) and Dyce et al. (2010) in dog and El-Bably and Tolba (2015) in cat reported that the extrinsic lingual muscles were styloglossus, hyoglossus and genioglossus. The reviewed article of Wedeen et al. (2001) in cattle had the opinion that the rostral part of the tongue consisted of an intrinsic muscle while its caudal aspect was composed of centrally located extrinsic lingual muscles distributed in a fan shaped appearance. Regarding the findings of Chibuzo (2006) and Saidu et al. (2015) in camel which were mentioned that the extrinsic lingual muscles entered the tongue from both sides.

The recent comparative work declared out that the styloglossus group comprised the minor and major parts. The former, was missed in the respected previous reviewed articles. The major one had an extra-glossal and intraglossal parts. The former arose by a short tendon from the distal end of stylohyoid process in cattle and buffalo while in camel by a longer tendenous band from the angular curvature of the stylohyoid process. A result which wasdifferent than that of El-Bably and Tolba (2015) in cat they had observed that the muscle encircled the upper third of the stylohyoid process. The present results revealed that the extraglossal part of the major styloglossus muscle, crossed the ventrolateral aspect of torus linguae. A finding which was nearly met by Miller et al. (1996), Dyce et al. (2010) and Köing and 
Liebich (2006) in dog and Saidu et al. (2015) in camel. The work recorded that the extra-glossal part of the muscle ended at the half level of torus linguae. While the intra-glossal one extended to the floor of the apex linguae. A result which is in contrast to that of the available literatures which considered that the styloglossus muscle ends at the middle of the tongue Chibuzo (2006) in camel, Köing and Liebich (2006) in dog, Saidu et al. (2015) in camel and El-Bably and Tolba (2015) in cat.

The comparative work recorded enforcement muscular band of longitudinal intrinsic fibers arose from the caudo-dorsal aspect of torus linguae. It joined the fibers of the intra-glossal part of the styloglossus muscle in cattle and buffalo, while it was absent in camel. These findings weren't reported in the reviewed articles.

Regarding the anatomical configuration of the hyoglossus muscle among cattle, buffalo and camel, the recent article reported that it arose from the basihyoid, thyrohyoid and lingual processes of the hyoid bone. Similar findings were cited by Miller et al. (1996), Köing and Liebich (2006) and Dyce et al. (2010) in dog. While it was attached to the basihyoid and thyrohyoid processes in camel. A result which differed from that mentioned by Saidu et al. (2015) in camel which had the opinion that it was originated from the lingual process, basihyoid and thyrohyoid processes.
On the other hand, the hyoglossus muscle was supported by thick muscular fibers from the lingual process of the hyoid bone to the rostral aspect of the muscle in cattle and buffalo. While in camel these fibers were absent and the fibers of the minor styloglossus muscle joined the caudal ones of the genioglossus muscle. A result which isn't mentioned by respected available literatures.

The genioglossus muscle of this study declared that it was erupted from a fossa caudal to the mandibular symphysis by a common tendon with the geniohyoid one. Nearly achieved findings were cited by Sisson and Grossman (1975) in horse and Chibuzo (2006) and Saidu et al. (2015) in camel. The genioglossus fibers ascended caudally in a fan shaped manner and grouped into rostral and caudal fibers; the former for the body of the tongue while the caudal ones for the root. Sisson and Grossman (1975) in horse had the opinion that it furnished three groups of fibers; rostral, middle and caudal. In the recently finished article, the eruption level of the muscle relative to the longitudinal axis of the mandible, differed in each species. So, in cattle it was more rostrally than that in buffalo while in camel it may arose near to the mid-point of the mandibular length. An adaptation that allows the effort of the muscle of camel to retreat than protrude the tongue and vice versa in cattle and buffalo Studying the anatomical structure of the 
geniohyoid muscle in the present work had a significant reason that the muscle affected the tongue movement. It attracted the lingual process of the hyoid bone with the root of the tongue rostrally in cattle and buffalo. Similar observations were cited by Sisson and Grossman (1975) in horse, and Evans and La Hunta (1996) in dog. Generally, the muscle was fusiform in cattle and buffalo while it was stout and triangular in camel.

It should be notified that the potency of the tongue was concluded from the enforcement supporting muscular fibers, role of the geniohyoid muscle and statistical data that determined the rational average between the tongue and different extrinsic muscles. The study scheduled the average data for each extrinsic muscle of the tongue. In this aspect, El-Bably and Tolba (2015) in cat cited a metrical data of the tongue and its lingual papillae and missed the extrinsic muscle. As well as the scheduled listed by Igado (2011) in dog which measured the dimensions of the whole tongue as a general. According to the metrical data in cattle, buffalo and camel were apparently similar and this was in agreement with the observations of Saidu et al. (2015) in camel. While this study suggested that the tongues of cattle and buffalo were stronger than that of camel. The anatomical configuration of the extrinsic lingual muscles in cattle and buffalo adapted their tongues for prolonged protrusion and flexible curving. On the other hand, the camel's tongue was

J. Vet. Anat. restricted intraorally. Similar results were concluded by Saidu et al. (2015) in camel.

\section{References}

Chibuzo, G.A. (2006): Ruminant dissection guide: a regional approach in the goats, second edition. Beth-Bekka Academic publishers Maiduguri Nigeria. Pp 61-64

Dyce, K.M., W.O. Sack, and C.J.G. Wensing. (2010): Textbook of veterinary anatomy. The digestive system, pp: 102-105.

Eerdunchaolu, Takehana, Yamamoto, Kobayashi, Cao, Baiyin, Ueda and Tangkawattana (2008): Characteristics of dorsal lingual papillae of the Bactrian camel (Camelusbactrianus). Anatomia, Histologia, Embryologia. Vol. 30 , issue 3

EI- Bably, S.H. \& Tolba, A.R. (2015): Morph-metrical studies on the tongue (Lingua) of the adult Egyptian domestic cats (Felisdomestica).

Evans, H.E., La Hunta, A. (1996): Miller's Guide to the Dissection of the Dog. 4th ed. W.B. Saunders Company, Philadelphia. 273-274.

Igado, O. O. (2011): Gross morphometric study of the eyeball and tongue of the Nigerian dog. IJAE Vol. 116, n. 1:104-110

Iwasaki, S. (2002): Evaluation of the structure and function of the vertebrate tongue J. Anat. 201, pp 1-13 
König, H.E. \& Liebich, H.G. (2006): Veterinary Anatomy of Domestic Mammals: Textbook and Colour Atlas, forth Edition.

Miller, M.E., GC Christensen, and H.E. Evans, (1996): Anatomy of the dog. WB Saunders Co, Philadelphia.

Parvez, M.N.H. \& Rahman, M.T. (2005): Anatomical study of the tongue of indigenous cow (Bosindicus) in Bangladesh with special emphasis on papillae distribution. Bangladesh journal of veterinary medicine. Vol. 3, No.2

Saidu, A., Jaji, A., Yawulda, P., U F., Da., Ahmed, Y. and Elelu, N. (2015). Gross morphology and morphometry of foetal and adult dromedary tongues. Sokoto journal of Veterinary Sciences, Vol. 13 No. 2

Shoeib, M.B., Risk, A.Z. and Hassanin, A.M. (2014): Comparative morphological studies on lyssa in carnivores and camels with special reference to its surgical resection. Journal of advanced veterinary research, Vol. 4, Issue 3. Pp 135-141.

Sisson and Grossman (1975): The anatomy of the domestic animals vol. $1,5^{\text {th }}$ edu WB Sanders

Co. Philadelphia.

Wedeen, V., J., Reese, T., G., Napadow, V., J. and Gilbert, R., J. (2001): Demonstration of primary and secondary muscle fiber architec- ture of the bovine tongue by diffuse tensor magnetic resonance imaging. Biophysical journal Vol. 80 1024- 1028

\section{Author address:}

anatomynazih@yahoo com 


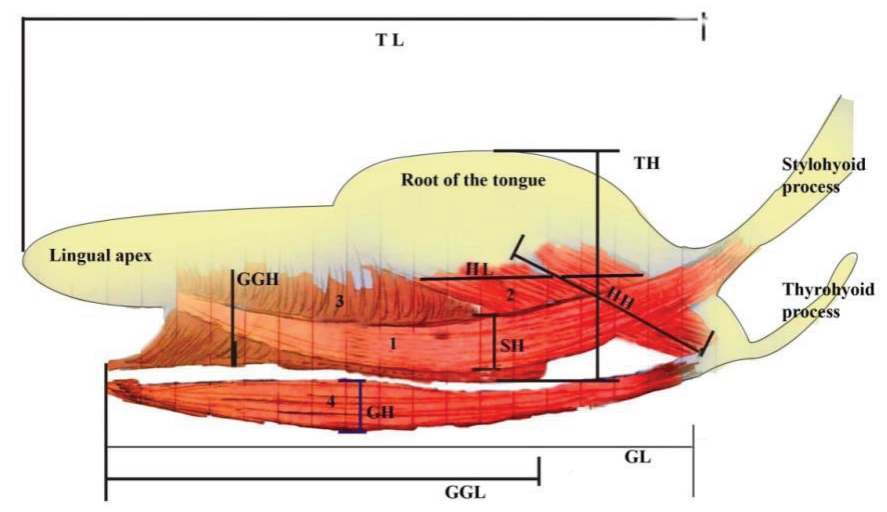

Fig (1): A Diagram showing standards of measurement of the extrinsic lingual muscles (Lateral view).

1Styloglossus M., 2 Hyoglossus M., 3 Genioglossus M., 4 Geniohyoideus M.

TL Tonguel ength, TH Tongue height, HL Hyoglossus length, $\mathrm{HH}$ Hyoglossus height, SH Styloglossus height, GGH Genioglossus height,GGLGenioglossus length, GHGeniohyoid height, GL Geniogyoid length.

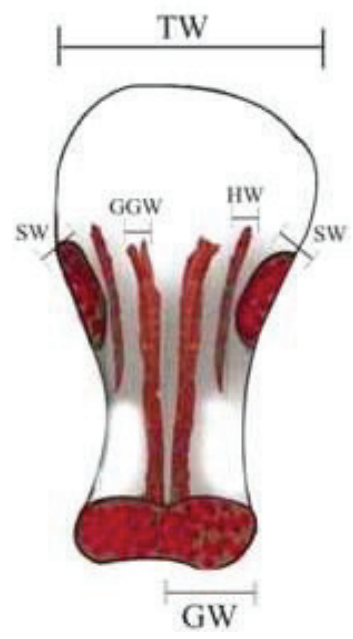

Fig (2): A Diagram showing standards of measurment of the extrinsic lingual muscles (Cross sectional view).

TW- Tongue width, SW- Styloglossus width, HW- Hyoglossus width, GGW- Genioglossus width, GW- Geniohyoid width. 


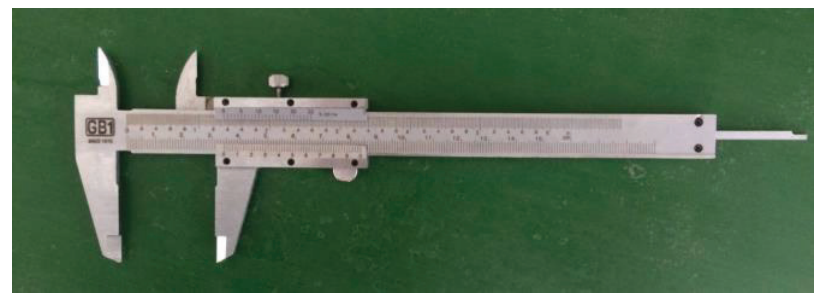

Fig (3): A photograph showing the Vernier caliper

Average ratios:

Statistical data of the tongue and extrinsic lingual muscles of cattle $(\mathrm{cm})$

\begin{tabular}{|c|c|c|c|c|c|c|c|c|c|c|c|c|c|c|c|}
\hline \multirow{2}{*}{ Head } & \multicolumn{3}{|c|}{ TONGUE } & \multicolumn{3}{|c|}{ Styloglossus } & \multicolumn{3}{|c|}{ Hyoglossus } & \multicolumn{3}{|c|}{ Genioglossus } & \multicolumn{3}{|c|}{ Geniohyoid } \\
\hline & $\mathrm{H}$ & $\mathrm{L}$ & W & $\mathrm{H}$ & L & W & $\mathrm{H}$ & L & W & $\mathrm{H}$ & L & W & $\mathrm{H}$ & L & W \\
\hline 1 & 10 & 29 & 7.5 & 3.2 & 21 & 1.7 & 5 & 5.6 & 0.8 & 4.8 & 17.7 & 0.8 & 1.5 & 15.5 & 2.5 \\
\hline 2 & 8.6 & 28.2 & 5.4 & 2.4 & 20.5 & 1.3 & 4.3 & 5.5 & 0.6 & 4.2 & 17.3 & 0.6 & 1.3 & 15 & 1.8 \\
\hline 3 & 11 & 32 & 8.3 & 3 & 23.2 & 1.9 & 5.5 & 6.2 & 0.9 & 5.3 & 19.6 & 0.9 & 1.6 & 17 & 2.7 \\
\hline 4 & 9 & 29.5 & 5.6 & 2.5 & 21.4 & 1.3 & 4.5 & 5.7 & 0.6 & 4.4 & 18 & 0.6 & 1.3 & 15.6 & 1.8 \\
\hline $\begin{array}{l}\text { Mean } \\
\text { values }\end{array}$ & 9.5 & 29.5 & 6.6 & 2.7 & 21.5 & 1.5 & 4.8 & 5.7 & 0.7 & 4.6 & 18.1 & 0.7 & 1.4 & 15.7 & 2.2 \\
\hline
\end{tabular}

Table 1: showing the metrical data of the tongue and the extrinsic muscles of cattle

\begin{tabular}{|c|c|c|c|c|c|c|c|c|c|c|c|c|c|c|c|}
\hline \multicolumn{16}{|c|}{ Statistical data of the tongue and extrinsic lingual muscles of buffalo $(\mathrm{cm})$} \\
\hline \multirow{2}{*}{ Head } & \multicolumn{3}{|c|}{ TONGUE } & \multicolumn{3}{|c|}{ Styloglossus } & \multicolumn{3}{|c|}{ Hyoglossus } & \multicolumn{3}{|c|}{ Genioglossus } & \multicolumn{3}{|c|}{ Geniohyoid } \\
\hline & $\mathrm{H}$ & L & w & $\mathrm{H}$ & $\mathrm{L}$ & W & $\mathrm{H}$ & L & w & $\mathrm{H}$ & L & w & $\mathrm{H}$ & L & w \\
\hline 1 & 8.8 & 39.3 & 7 & 2.4 & 27.7 & 0.9 & 8.2 & 6.7 & 0.9 & 5.6 & 24.3 & 0.6 & 1.7 & 24.4 & 1.7 \\
\hline 2 & 9.2 & 41 & 7.3 & 2.5 & 28.8 & 0.9 & 8.5 & 7 & 0.9 & 5.8 & 25.4 & 0.6 & 1.7 & 25.2 & 1.7 \\
\hline 3 & 9 & 40 & 7.1 & 2.4 & 28 & 0.9 & 8.3 & 6.8 & 0.9 & 5.7 & 24.8 & 0.6 & 1.6 & 24.5 & 1.6 \\
\hline 4 & 9.4 & 41.7 & 7.4 & 2.5 & 29.2 & 0.93 & 8.6 & 7.1 & 0.9 & 5.9 & 25.9 & 0.6 & 1.6 & 25.5 & 1.6 \\
\hline $\begin{array}{l}\text { Mean } \\
\text { values }\end{array}$ & 9.1 & 40.5 & 7.2 & 2.4 & 28.4 & 0.9 & 8.4 & 6.9 & 0.9 & 5.7 & 25.1 & 0.6 & 1.6 & 22.4 & 1.6 \\
\hline
\end{tabular}

Table 2: showing the metrical data of the tongue and the extrinsic muscles of buffalo

\begin{tabular}{|c|c|c|c|c|c|c|c|c|c|c|c|c|c|c|c|}
\hline \multicolumn{16}{|c|}{ Statistical data of the tongue and extrinsic lingual muscles of camel $(\mathrm{cm})$} \\
\hline \multirow{2}{*}{ Head } & \multicolumn{3}{|c|}{ TONGUE } & \multicolumn{3}{|c|}{ Styloglossus } & \multicolumn{3}{|c|}{ Hyoglossus } & \multicolumn{3}{|c|}{ Genioglossus } & \multicolumn{3}{|c|}{ Geniohyoid } \\
\hline & $\mathrm{H}$ & L & W & $\mathrm{H}$ & L & W & H & L & W & $\mathrm{H}$ & L & W & $\mathrm{H}$ & L & W \\
\hline 1 & 10.1 & 33.1 & 4.3 & 1.5 & 28.2 & 0.4 & 9.5 & 5.8 & 0.3 & 6.2 & 18 & 0.6 & 2.1 & 18.8 & 2.5 \\
\hline 2 & 10.4 & 34 & 4.4 & 1.5 & 29 & 0.4 & 9.7 & 5.9 & 0.3 & 6.3 & 18.5 & 0.6 & 2.1 & 19.3 & 2.5 \\
\hline 3 & 9.8 & 32 & 4.1 & 1.4 & 27.3 & 0.3 & 9.1 & 5.5 & 0.3 & 5.9 & 17.4 & 0.6 & 1.9 & 18.1 & 2.3 \\
\hline 4 & 10.2 & 33.3 & 4.2 & 1.4 & 28.4 & 0.3 & 9.4 & 5.7 & 0.3 & 6.1 & 18 & 0.6 & 1.9 & 18.8 & 2.3 \\
\hline $\begin{array}{l}\text { Mean } \\
\text { values }\end{array}$ & 10.1 & 33.1 & 4.2 & 1.4 & 28.2 & 0.3 & 9.4 & 5.7 & 0.3 & 6.1 & 17.9 & 0.6 & 2 & 18.7 & 2.4 \\
\hline
\end{tabular}

Table 3: Showing the metrical data of the camel tongue and its extrinsic muscles 
Styloglossus M.

\begin{tabular}{|c|c|c|c|}
\hline Species & TL:SL & TH:SH & TW:SW \\
\hline Cattle & $1: 0.7$ & $1: 0.3$ & $1: 0.2$ \\
& & & $1: 0.1$ \\
\hline Buffalo & $1: 0.7$ & $1: 0.2$ & $1: 0.1$ \\
\hline Camel & $1: 0.8$ & $1: 0.1$ & \\
\hline
\end{tabular}

Table 4: showing the average ratios of styloglossus muscle with the tongue Hyoglossus M.

\begin{tabular}{|c|c|c|c|}
\hline Species & TL:HL & TH:HH & TW:HW \\
\hline Cattle & $1: 0.2$ & $1: 0.5$ & $1: 0.1$ \\
\hline Buffalo & $1: 0.17$ & $1: 0.9$ & $1: 0.1$ \\
\hline Camel & $1: 0.2$ & $1: 0.9$ & $1: 0.1$ \\
\hline
\end{tabular}

Table 5: showing the average ratios of hyoglossus muscle with the tongue

Genioglossus M.

\begin{tabular}{|c|c|c|c|}
\hline Species & TL:GL & TH:GH & TW:GW \\
\hline Cattle & $1: 0.6$ & $1: 0.5$ & $1: 0.1$ \\
\hline Buffalo & $1: 0.6$ & $1: 0.6$ & $1: 0.08$ \\
\hline Camel & $1: 0.5$ & $1: 0.6$ & $1: 0.1$ \\
\hline
\end{tabular}

Table 6: showing the average ratios of genioglossus muscle with the tongue 

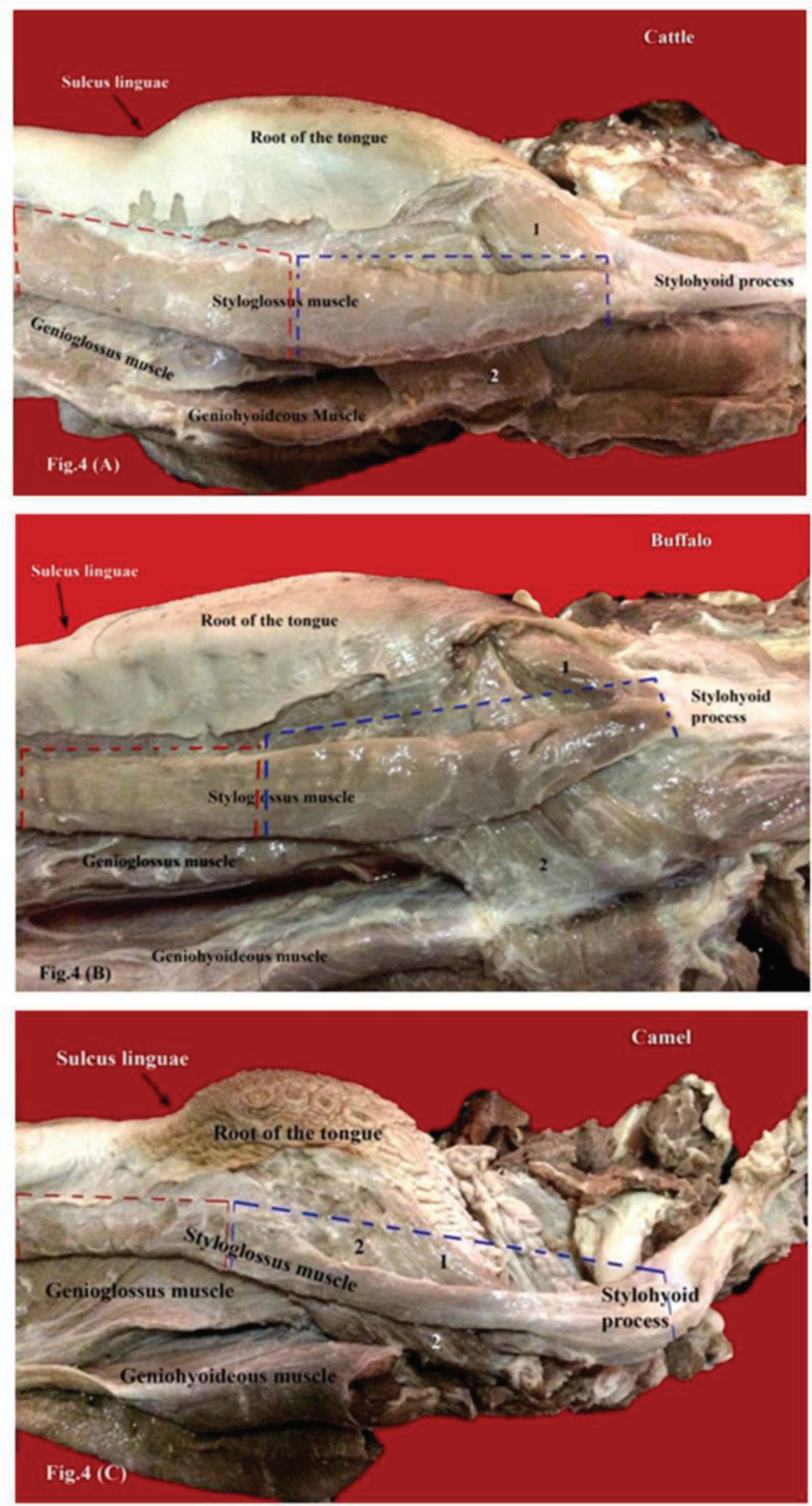

Fig (4): A photograph showing the extrinsic lingual muscles (A Cattle, B Buffalo, C Camel)1- Minor styloglossus 2- Hyoglossus muscle. The dotted blue area is the extra-glossal part of styloglossus $\mathrm{M}$. The redish area is the intra-glossal part of styloglossus $\mathrm{M}$. 

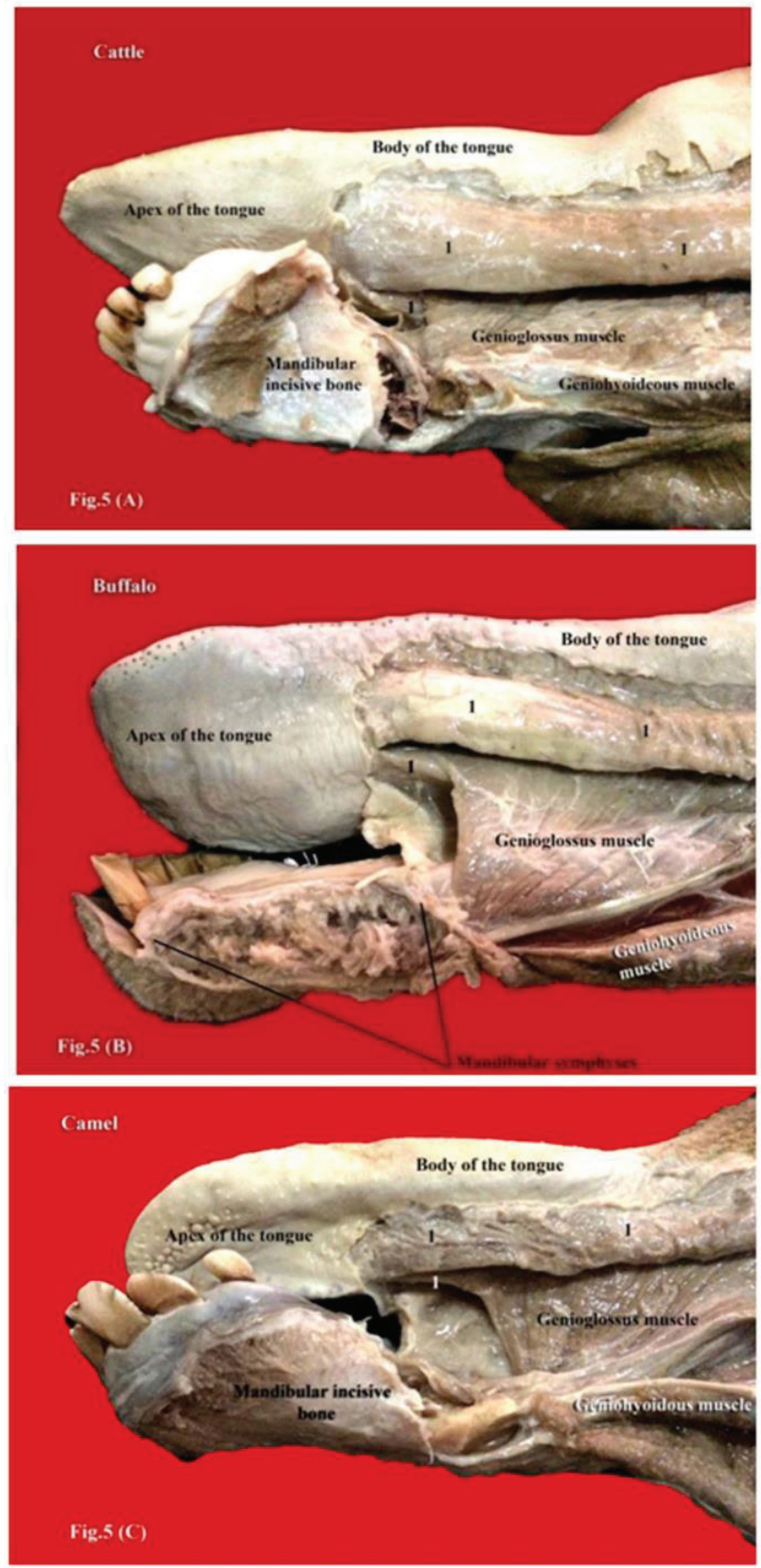

Fig (5): A photograph showing the extrinsic lingual muscles (rostral view) (A Cattle, B Buffalo, C Camel)

1- Intraglossal part of styloglossus muscle 

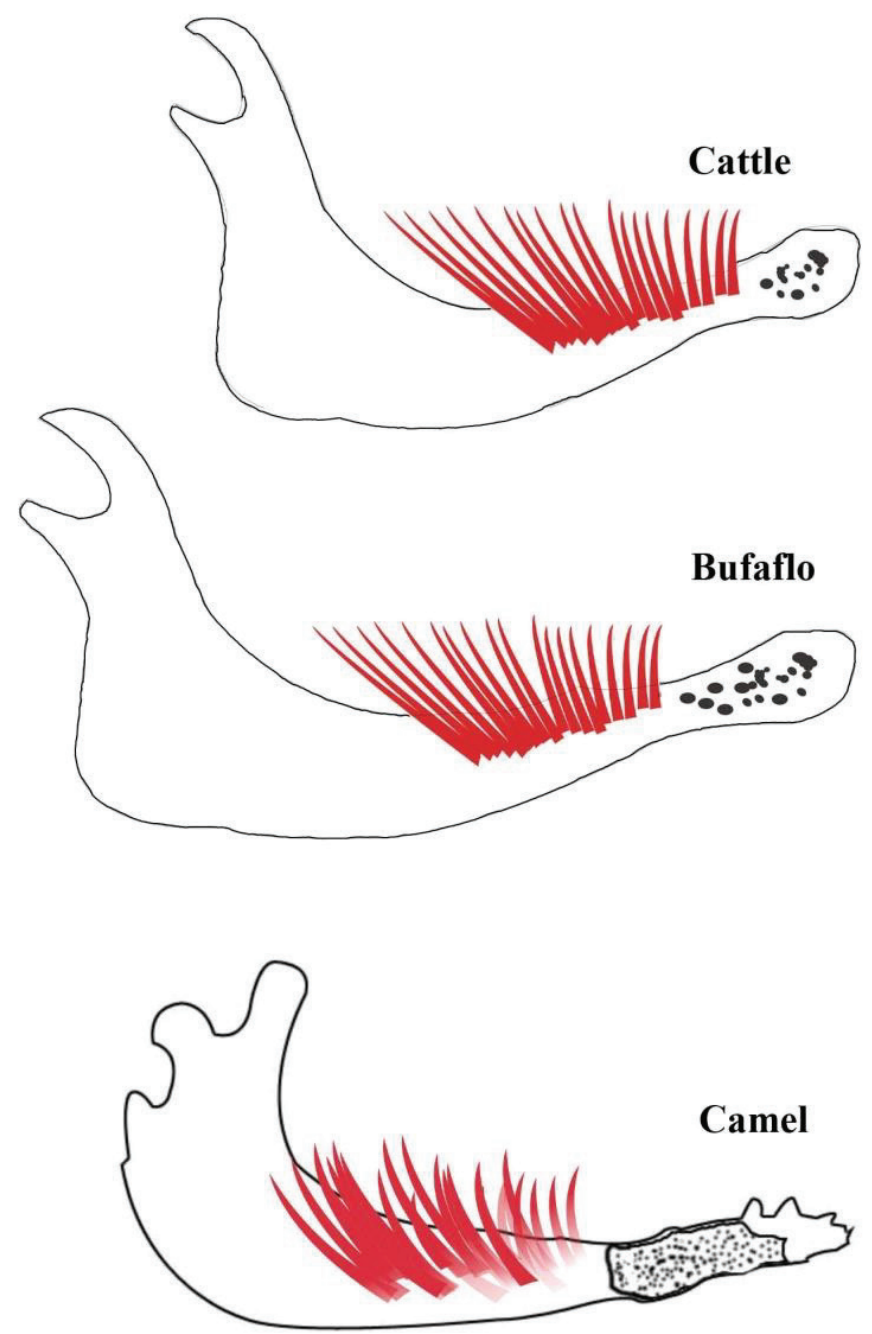

Fig (6): A diagram showing the eruption level of the genioglossus muscle (red colored) in the mandible of cattle, buffalo, and camel. 
Extrinsic lingual muscle fibers in cattle, buffalo and camel

Nazih, M. A.
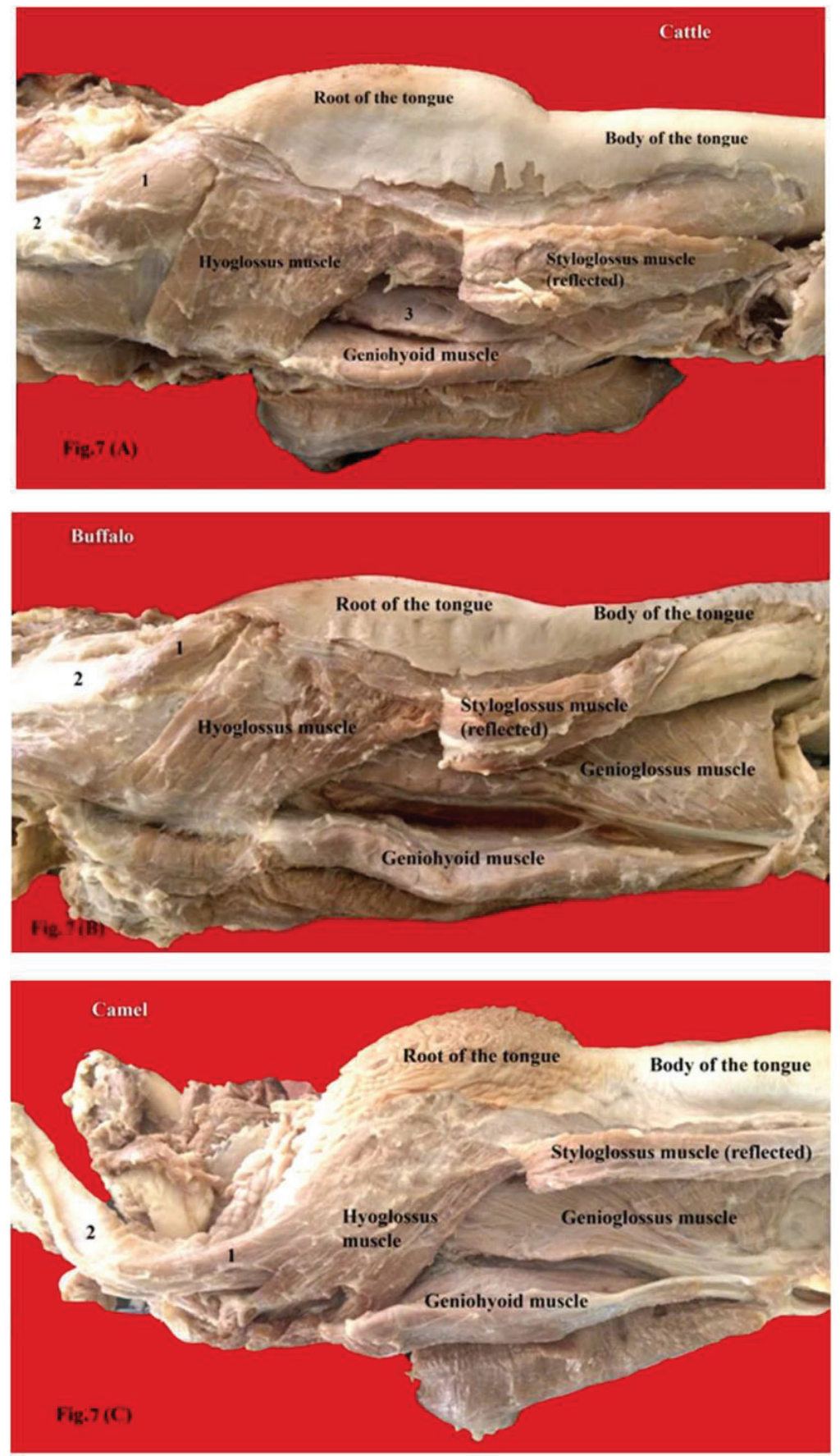

Fig (7): A photograph showing the extrinsic lingual muscles (Right side) (A Cattle, B Buffalo, C Camel)

1- Minor styloglossus muscle 2- Stylohyoid process 3- Genioglossus muscle 

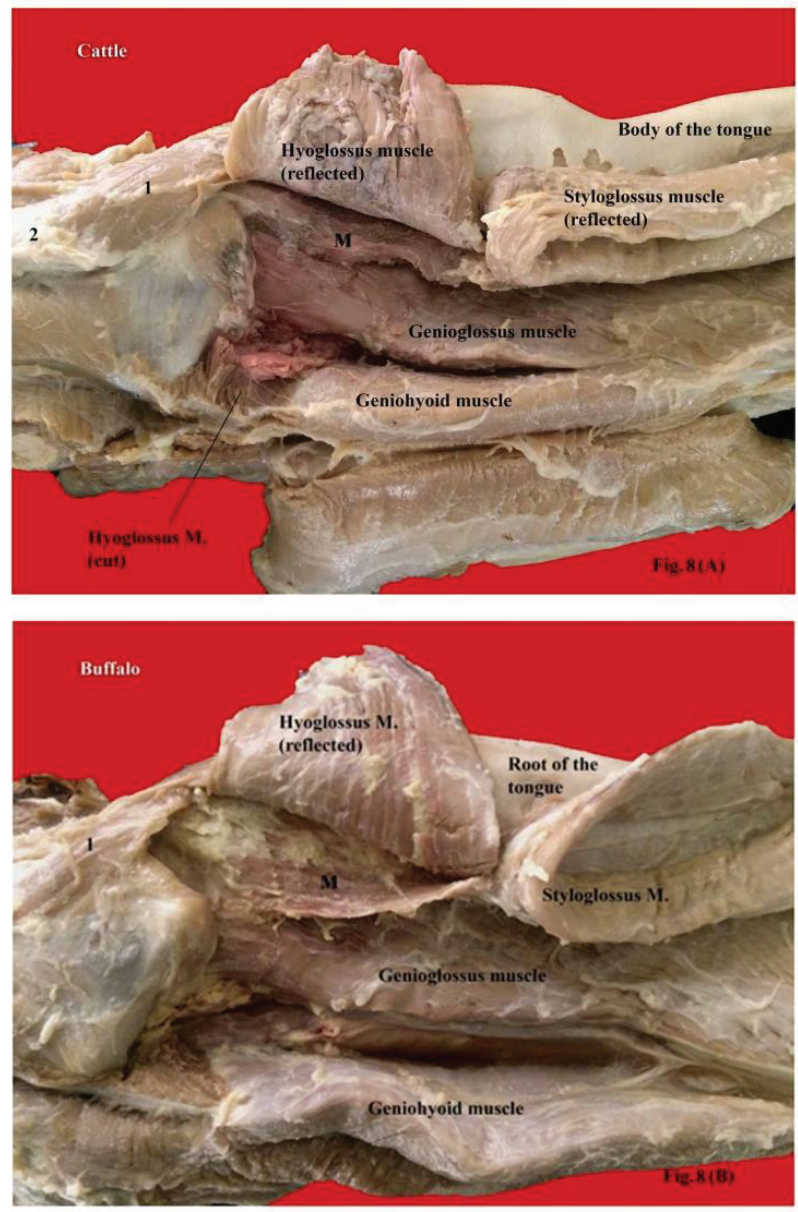

Fig (8): A photograph showing the extrinsic lingual muscle deep dissection (Right side) (Cattle, Buffalo,)

1- Minor styloglossus muscle.

2- Stylohyoid process M- longitudinal muscular band 
Extrinsic lingual muscle fibers in cattle, buffalo and camel

Nazih, M. A.

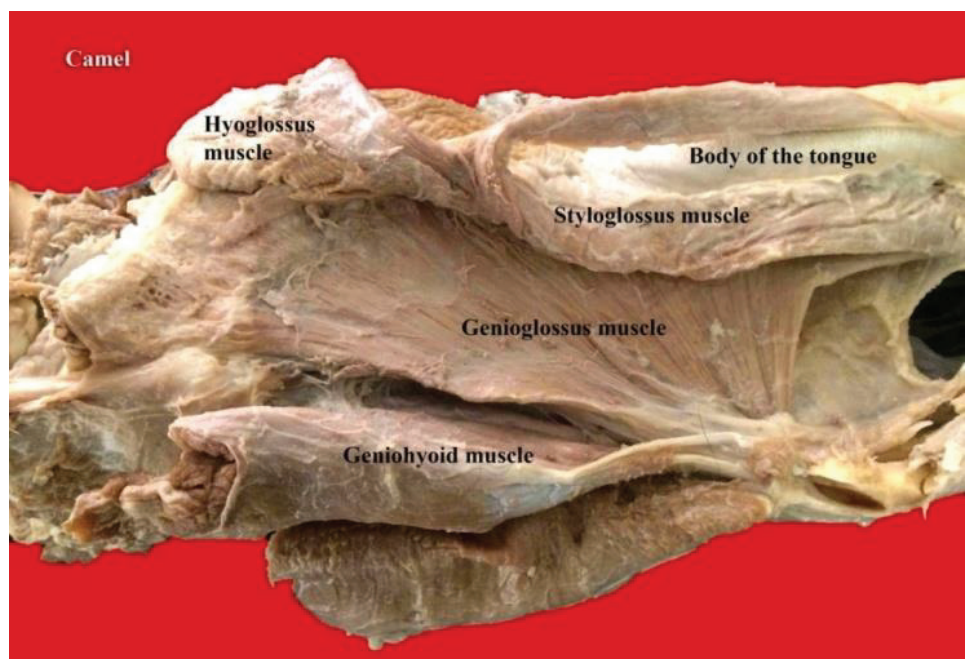

Fig (9): A photograph showing the extrinsic lingual muscles deep dissection, Right side (Camel). 